(c) American Dairy Science Association, 2006.

\title{
Characterization of Holstein Heifer Fertility in the United States
}

\author{
M. T. Kuhn, J. L. Hutchison, and G. R. Wiggans \\ Animal Improvement Programs Laboratory, Agricultural Research Service, USDA, Beltsville, MD 20705-2350
}

\begin{abstract}
The overall object of this research was to characterize US Holstein (virgin) heifer fertility. This included investigation of factors influencing heifer fertility and estimation of heritability, as well as correlations with cow fertility and first-lactation milk yield. A secondary objective was to compare linear and logistic model estimates of fixed effects and linear and threshold model estimates of heritability. Data consisted of Holstein heifers, which were artificially inseminated, with their first breeding between March 2003 and August 2005. Herds were required to have at least 60 breedings across the $3 \mathrm{yr}$ of data and an overall mean conception rate (CR) between 20 and $80 \%$. After edits there were 537,938 breedings of 362,512 heifers in 2,668 herds from 41 states used for analysis. After edits, the overall mean CR for US Holstein heifers was 57\%. Linear and logistic model estimates for all factors were nearly identical. Year of breeding accounted for the most variation in heifer CR, with heifer age and month of breeding being the next most important factors. Conception rate in heifers is maximal at an intermediate age of 15 to 16 mo. Heifers at 26 mo of age and older have roughly a $10 \%$ lower CR than heifers bred at younger ages. Although month of breeding affected heifer CR, effects are less than for cows. In contrast to cow fertility, heifer $\mathrm{CR}$ is nearly as good in the hotter summer months as in cooler months. Approximately $88 \%$ of US herds had a 40 to $70 \%$ heifer CR. Heritability estimates of heifer $\mathrm{CR}$ on first service were $0.5 \%$ from the linear model and $1.0 \%$ from the threshold model. Genetic correlation estimates of heifer CR on first service with cow CR on first service and with first-lactation milk yield were 0.39 and -0.19 , respectively. Results indicated that selection on either the currently available US daughter pregnancy rate evaluations for cow fertility or on cow $\mathrm{CR}$ will also improve heifer fertility. Furthermore, heritability of heifer CR is lower than for cow CR and reporting of heifer breedings is currently less complete than for cow breedings. Thus, there are currently no
\end{abstract}

Received April 17, 2006.

Accepted July 6, 2006.

${ }^{1}$ Corresponding author: mkuhn@aipl.arsusda.gov immediate plans to implement a US genetic evaluation for heifer CR.

Key words: heifer fertility, conception rate, genetic correlation, threshold model

\section{INTRODUCTION}

Selection for higher production in US dairy cattle has been quite successful in increasing mean yield over the last $40 \mathrm{yr}$. The Animal Improvement Programs Laboratory (AIPL) estimates a national increase of $3,259 \mathrm{~kg}$ in breeding value for milk yield between 1963 and 2003 for US Holsteins (AIPL, 2005). However, the antagonistic genetic correlation of cow fertility, as measured by days open (DO), with milk yield is about 0.35 (VanRaden et al., 2004). Thus, selection on milk yield without concomitant selection on fertility has resulted in a decline in cow fertility, in spite of relatively low heritabilities for reproductive traits. National estimates indicate a phenotypic increase of about 38 DO between 1960 and 2000 and an increase in breeding value for $\mathrm{DO}$ of about $16.5 \mathrm{~d}$ over the same period (AIPL, 2005). Thus, interest in cow fertility has risen considerably in recent years, as evidenced by a plethora of popular press articles as well as scientific research. In response to the decline in fertility and increased concern about cow fertility, AIPL implemented a national US genetic evaluation for cow fertility in February 2003 (VanRaden et al., 2004). This new AIPL cow fertility evaluation is called daughter pregnancy rate (DPR) and is based on DO.

Although considerable research has now been done on cow fertility, far less has been done on (virgin) heifer fertility, especially in the United States. It is difficult, for example, to find even a basic description of the status of US heifer fertility, even something as simple as mean heifer conception rate $(\mathbf{C R})$. Much of the literature that is available on US heifer fertility is based on small samples or single herds. This paucity of research, at least in the US, has perhaps been due, in part, to lack of a central database for heifer breeding data. Before 2003, the only fertility information available in the national, AIPL database was for DO and, thus, only for first and later lactations. In 2003, however, AIPL finalized a new reproductive record, called Format 5, which provided a means for dairy record processing centers 
to supply information on individual breedings for both cows and heifers. This new breeding record allows reporting of date of insemination, service sire, type of mating (AI or natural service) and service number, along with the usual animal identification information (breed, herd, animal identification). In addition to the information on individual breedings, heats, synchronizations, embryo transfers (donations and implantations), results of pregnancy exams, and "do not breed" designations can also be reported on the new Format 5 record. Receipt of this data began approximately October 2003, although only 2 of the 4 major processing centers (Dairy Records Management Systems, Raleigh, NC; and AgSource, Verona, WI) are currently sending Format 5 data; these processing centers account for about $78 \%$ of US herds on test and about $57 \%$ of the lactating cows on test. This new reproductive data, which includes information on heifer breedings, affords new opportunities for fertility research.

The overall purpose of this research was to characterize US Holstein (virgin) heifer fertility. In addition to a basic description of the data that has been received, this characterization included 2 general aspects. The first part involved assessment of factors affecting heifer fertility. Identification of such factors is needed for modeling purposes and can also be useful for management as well as mating programs. The effects of season and age-at-breeding, for example, could be useful in management decisions and inbreeding effects could be useful in mating programs. The second part of this characterization was to estimate heritability as well as correlations with cow fertility and first-lactation milk yield. Several countries have implemented a genetic evaluation for heifer fertility (Jorjani, 2005). Heritabilities and correlations assist in determining the usefulness of heifer fertility in a breeding program. A secondary objective was to compare linear and nonlinear models for the binary trait CR; logistic model estimates were compared with linear model estimates for factors affecting fertility and linear and threshold model parameter estimates were compared.

\section{MATERIALS AND METHODS}

\section{Description of Data Received}

Although analyses of data involved only Holstein heifers, the overall summary of the data that has been received included all breeds. Edits for this initial data summary were minimal. For matings that were less than $10 \mathrm{~d}$ apart, only the later mating was kept. Personal communications with reproductive specialists who advise dairy producers suggested that repeat matings within short intervals are generally the result of misdiagnosed heats on the first insemination or per- haps that the animal was bred on a timed AI program and was later observed in heat. Of course it is possible that the second breeding in a short time would be a breeding to a pregnant animal that is not in heat but such a mistake presumably occurs much less frequently than a "first" breeding based on a false heat or timed AI; hence, only the second of 2 matings that occurred close in time were kept.

To ensure adequate time for a repeat mating to be reported, matings were included only if the herd had a test-day of $70 \mathrm{~d}$ or more after the reported breeding date. Finally, a maximum of 7 services per heifer was imposed; services beyond 7 were excluded and accounted for only $0.25 \%$ of all breedings. The data summary included number of breedings, frequency of AI vs. natural service, number of matings by year, and the arithmetic means and standard deviations of CR for each breed. The proportion of herds reporting heifer breedings for the year 2003 was also determined.

One source of uncertainty with data on individual breedings can be whether the service was a success or failure. Although this uncertainty pertains primarily to the last service on file (virtually all other breedings can be assumed failures), each mating was assigned a "confirmation code" (e.g., confirmed open/failure, confirmed pregnant/success, unknown) and code frequencies were calculated as a further description of available data. Six confirmation codes were defined: 1 ) confirmed open by the occurrence of a subsequent reproductive event (another breeding, heat, or confirmed open by pregnancy check); 2) confirmed open by a subsequent calving date because calving date disagreed with breeding date; 3) confirmed open because enough time (365 d) had expired for the heifer to have a reported calving, the herd was still on test, and no calving had been reported; 4) confirmed pregnant by a pregnancy examination; 5) confirmed pregnant by subsequent calving (actual and expected calving dates agreed within 14 d); and 6) unknown because there were no subsequent reproductive events (including a pregnancy check) recorded and sufficient time had not yet expired for a calving to have been reported. For confirmation code 2, the difference between the expected calving date (breeding date plus $280 \mathrm{~d}$ ) and the actual calving date had to differ by more than $14 \mathrm{~d}$ for the mating to be considered a failure. Matings with an unknown confirmation code were treated as successes because after $70 \mathrm{~d}$ either the heifer was culled or is likely pregnant to the reported breeding, which is akin to the often-used idea of nonreturn rate.

\section{Factors Affecting Heifer Fertility}

The effects of 12 factors on heifer CR were investigated in this research: herd, AI year, AI month, age of 
heifer at breeding, age of service sire at breeding, stud (AI organization) of service sire, inbreeding in the heifer, inbreeding of the mating (potential embryo), inbreeding of the service sire, breed of service sire, parent average estimated breeding value for DPR, and service number. The model equation used to estimate the effects for most of these factors was:

$$
\begin{gathered}
\mathrm{y}=\text { herd + AIyr + AImo + HefAgeGrp + SsrAgeGrp } \\
+ \text { Stud + HefInbrdGrp + MtgInbrdGrp } \\
+ \text { SsrInbrdGrp + SsrAgeGrp } \times \text { SsrInbrdGrp + e }
\end{gathered}
$$

where y was the binary result of an AI breeding $(0=$ failure, $1=$ success), AIyr and AImo were year and month of breeding, respectively; HefAgeGrp and SsrAgeGrp were the ages at breeding, fit as classification variables, for the heifer and service sire, respectively; Stud was the AI organization at which the service sire was maintained; HefInbrdGrp, MtgInbrdGrp, and SsrInbrdGrp were the effects of inbreeding, fit as classification variables, for heifer, mating, and service sire, respectively; and SsrAgeGrp $\times$ SsrInbrdGrp was the interaction between those 2 factors. All factors were fit as fixed effects. There were 9 levels used for heifer age groups, 4 levels for service sire age, 5 for heifer and mating inbreeding, and 4 levels for service sire inbreeding. Age and inbreeding effects were fit as categorical variables rather than covariates to allow for the possibility of nonlinear relationships with CR. Using covariates to model nonlinear relationships can be cumbersome because the use of covariates assumes a particular nature for the relationship; a quadratic regression, for example, necessarily implies a parabolic relationship. Inbreeding depression, for instance, may increase at a decreasing rate (as described by Thompson et al., 2000, for milk yield) but it is unlikely that the effect of inbreeding peaks at a certain point and then actually benefits the trait at higher levels, which would be implied by use of a quadratic regression. Use of categorical variables also allows for more readily interpretable interactions amongst factors of interest.

Parent average DPR was missing for a sizeable proportion of the observations and service sire breed would have been confounded with mating inbreeding. Thus, these factors were fit in subsequent analyses to allow the maximum amount of data to be used in investigating the other 9 factors. Parent average DPR was simply added to Equation [1] to determine its association with heifer CR. For service sire breed, the model included herd, AI year, AI month, age at breeding of the heifer, service sire age at breeding, heifer inbreeding, and, of course, service sire breed.
Conception rate by service number was also estimated by adding service number to Model [1] in a supplemental analysis, using confirmed matings only. It is not likely that service number per se has an effect on $\mathrm{CR}$; if a heifer was being bred for the third time, for example, it is unlikely that the previous 2 breedings have any effect on the outcome for the third. Furthermore, the general result of lower CR with increasing service number can be anticipated because only heifers that are more difficult to breed will have breedings at higher service numbers. However, mean CR by service number can be useful for management purposes, and in particular for determining at what point a heifer is subfertile and perhaps unlikely to conceive on any mating. If, for example, CR on fifth and later services was only $20 \%$, then one would conclude that after 4 breedings there is little utility in further breedings, and that the heifer should be culled or checked by a veterinarian for reproductive or health problems.

Data were restricted to matings of Holstein heifers with a known Holstein service sire; if service sire was not recorded, the mating was deleted. About $6 \%$ of the matings between March 2003 and August 2005 were missing service sire. Because collection of data did not begin until approximately October 2003, records before 2003 were sparse. Furthermore, the number of breedings before March 2003 was considerably lower than for year-months thereafter. Thus, only heifers first bred between March 2003 and August 2005 were included. Matings from September 2005 were excluded because they would have only included heifers that failed to breed in earlier months and, therefore, would have biased estimates of month effects. Breedings were also restricted to heifers between the ages of 11 and $27 \mathrm{mo}$. There were very few breedings outside of the range of 11 to 27 mo of age.

Herds had to have at least 60 breedings across the $3 \mathrm{yr}$ of data included and an overall mean CR between 20 and $80 \%$. The edit on herd CR was done to eliminate herds with incomplete reporting; for example, herds that report successful (final) breedings only. To avoid problems with small group sizes, heifers bred to bulls with birth years before 1985 or to bulls whose inbreeding coefficient was greater than $15 \%$ were also eliminated; such matings were rare $(0.18 \%$ of edited data) and at least some of those that did exist may have been recording errors. After edits, there were only 1,675 natural service matings available. Thus, AI matings only were used in this research.

In contrast, for example, to using first service only, all available breedings of a heifer were used in this study. After edits there were 537,938 AI breedings of 362,512 heifers in 2,668 herds from 41 states used for analysis. The overall arithmetic mean CR of the edited 
data was $57.0 \%$, with $4.3 \%$ of the breedings unconfirmed. A subsequent analysis utilized only heifers that had all matings confirmed to determine the impact of unconfirmed matings on the differences among levels for the factors in Model [1].

For comparison, Model [1] was fit as both a linear and logistic model. The GLM and Genmod procedures of SAS were used to fit the linear and logistic models, respectively (SAS Institute, 2004). Type III mean squares from the linear model are listed alongside type III likelihood ratio statistics from the logistic model to compare how the 2 models ranked each factor in the analysis and to compare significance tests from the 2 analyses. Least squares means from the linear model, for each effect except herd, were compared with least squares means from the logistic model. The Genmod procedure computes requested least squares means on the underlying scale in the same manner as GLM does for a linear model. Least squares means for the logistic model, then, were those computed by Genmod but then transformed (exponentiated; i.e., exp(lsm_log)/[1 + $\left.\exp \left(\operatorname{lsm} \_l o g\right)\right]$, where lsm_log denotes the least squares mean on the underlying scale) to the observed scale. Herd means from the linear model were summarized with a frequency distribution.

\section{Parameter Estimation}

For comparison, heritabilities for heifer CR were estimated from both a linear and a threshold model. Heritability was estimated for both first service only and all services. The model equation for all services was:

$$
\begin{gathered}
\mathrm{y}=\mathrm{HY}+\text { YR-ST-MO }+ \text { Age }+ \text { ServNum } \\
+\mathrm{PE}+\mathrm{G}+\mathrm{e},
\end{gathered}
$$

where y was success or failure of breeding, HY was herd-year of breeding, YR-ST-MO was year-statemonth of breeding, Age was age at breeding fit as a categorical variable, ServNum was service number, $\mathrm{PE}$ was a permanent environmental effect to account for the additional (beyond genetic) correlation between repeated services on the same heifer, and $\mathrm{G}$ was a genetic effect (animal for the linear model and sire for the threshold model). The variance-covariance matrix for G was $\mathbf{A} \sigma_{\mathrm{g}}^{2}$, where $\mathbf{A}$ was a relationship matrix including animal, sire, dam for the linear animal model and sire, sire-of-sire, maternal-grandsire-of-sire for the threshold sire model; $\sigma_{\mathrm{g}}^{2}$ was the scalar additive variance for the animal model and sire variance for the sire model. The variance-covariance structure for $\mathrm{PE}$ and error was $\mathrm{I} \sigma^{2}$, where $\sigma^{2}$ was the scalar PE or error variance. The model for first services only was the same as [2] but without service number and permanent environment.
Only a sample of the data that was used to study factors affecting CR was used for parameter estimation because the entire data set was more than could be handled computationally. Herds were randomly selected for inclusion. To make results directly comparable, the exact same data was used for the linear and threshold models and the data for first service only was the same as that for all services but using only the first breeding for each heifer. The sample for estimation of heritability for all services contained 95,741 breedings of 62,128 heifers from 522 herds. Estimates of heritability were based on confirmed matings only, although, for comparison, unconfirmed matings were included in a subsequent analysis for the linear model.

Due to convergence problems with the threshold model, genetic correlations of heifer CR on first service with cow CR on first service and with first-lactation milk yield were estimated with a linear animal model only. The model equation for estimation of the genetic correlation between heifer and cow $\mathrm{CR}$ on first service was:

$$
\left(\begin{array}{l}
\mathbf{y}_{1} \\
\mathbf{y}_{2}
\end{array}\right)=\left(\begin{array}{cc}
\mathbf{X}_{1} & \mathbf{0} \\
\mathbf{0} & \mathbf{X}_{2}
\end{array}\right)\left(\begin{array}{l}
\mathbf{b}_{1} \\
\mathbf{b}_{2}
\end{array}\right)+\left(\begin{array}{cc}
\mathbf{Z}_{1} & \mathbf{0} \\
\mathbf{0} & \mathbf{Z}_{2}
\end{array}\right)\left(\begin{array}{l}
\mathbf{u}_{1} \\
\mathbf{u}_{2}
\end{array}\right)+\left(\begin{array}{l}
\mathbf{e}_{1} \\
\mathbf{e}_{2}
\end{array}\right)
$$

where $\mathbf{y}_{1}$ and $\mathbf{y}_{2}$ were vectors of records for heifers and cows, respectively; $\mathbf{b}_{1}$ and $\mathbf{b}_{2}$ were vectors of fixed effects; $\mathbf{u}_{1}$ and $\mathbf{u}_{2}$ were vectors of breeding values; and $\mathbf{e}_{1}$ and $\mathbf{e}_{2}$ were vectors of errors. Animals in $\mathbf{y}_{2}$ (cow records) were also in $\mathbf{y}_{1}$ (heifer records); i.e., the cow records were only those who also had heifer breedings. Fixed effects common to both heifer and cow records were herd-year of breeding, year-state-month of breeding, and age at breeding fit as a categorical variable. Days in milk at first breeding was included as a categorical variable for cow $\mathrm{CR}$ as well. The variance-covariance matrix for the vector $\mathbf{u}^{\prime}=\left[\begin{array}{ll}\mathbf{u}_{1}^{\prime} & \mathbf{u}_{2}^{\prime}\end{array}\right]$ was:

$$
\operatorname{Var}(\mathbf{u})=\left(\begin{array}{cc}
\mathbf{A} \sigma_{\mathrm{a} 1}^{2} & \mathbf{A} \sigma_{\mathrm{a} 1 \mathrm{a} 2} \\
\mathbf{A} \sigma_{\mathrm{a} 1 \mathrm{a} 2} & \mathbf{A} \sigma_{\mathrm{a} 2}^{2}
\end{array}\right)
$$

where $\mathbf{A}$ was a relationship matrix containing animal, sire, dam; $\sigma_{\mathrm{a} 1}^{2}$ and $\sigma_{\mathrm{a} 2}^{2}$ were scalar genetic variances and $\sigma_{\mathrm{a} 1 \mathrm{a} 2}$ was the scalar genetic covariance. The model equation for estimation of the genetic correlation of heifer CR on first service with first-lactation milk yield was the same as [3] except that DIM was not included as a fixed effect for cows. A preliminary analysis indicated a zero correlation between errors; therefore, the error correlation was fixed at zero and not estimated in the final analyses. Although these traits are measured on the same animals, they occur at different points in time; 
Table 1. Number of heifer breedings, mean conception rate (CR), and standard deviation of CR, by breed

\begin{tabular}{lrll}
\hline & & $\begin{array}{l}\text { Mean } \\
\mathrm{CR}^{1} \\
(\%)\end{array}$ & $\begin{array}{c}\text { SD } \\
(\%)\end{array}$ \\
\hline Breed & $\mathrm{n}$ & 47.9 & 50.0 \\
Ayrshire & 2,379 & 47.5 & 49.9 \\
Drown Swiss & 5,779 & - & - \\
Dutch Belted & 53 & 43.6 & 49.6 \\
Holstein & 2,226 & 56.3 & 49.6 \\
Jersey & 871,835 & 52.2 & 50.0 \\
Lineback & 39,972 & 38.7 & 48.8 \\
Montbeliarde & 462 & - & - \\
Milking Shorthorn & 6 & 59.3 & 49.2 \\
Normande & 450 & - & - \\
Norwegian Red & 4 & - & - \\
Red Dane & 39 & - & - \\
European Red Dairy & 7 & - & - \\
Red Poll & 3 & - & - \\
Simmental & 7 & - & 49.6 \\
Holstein Red and White & 8 & 56.6 & 49.1 \\
Crossbred & 629 & 59.2 & \\
\hline
\end{tabular}

${ }^{1}$ Overall, arithmetic mean for breeds with at least 100 matings.

thus, the zero error correlation simply reflected no correlation of environmental effects across time.

The same sample was used to estimate genetic correlations of heifer $\mathrm{CR}$ with cow $\mathrm{CR}$ and first-lactation milk yield. To avoid potential bias due to culling, heifers were not required to have a cow record to be included for estimation of correlations. The sample for estimation of correlations contained 51,368 heifer breedings and 22,452 cow breedings and first-lactation milk records. Heifers without cow records were either culled as heifers, had not had sufficient time calve, or, if they had calved, either were not bred in first lactation (cull cows) or had not yet received a breeding in first lactation. Restricted maximum likelihood was used for estimation of both heritabilities and correlations.

\section{RESULTS AND DISCUSSION}

\section{Description of Data Received}

The total number of matings reported as of September 2005 are given in Table 1 for each breed. By far, the majority (94\%) was Holstein, whereas the second most common breed (Jerseys) accounted for $4 \%$ of all matings. The number of heifer matings reported for all other breeds was quite low. In regard to type of mating, $95 \%$ of all reported matings were $\mathrm{AI}$ and only $5 \%$ were natural service. Over the entire United States, 29\% of herds on test have reported heifer breedings and these herds accounted for $32 \%$ of all lactating cows on test. For herds enrolled with Dairy Records Management Systems or AgSource, 38.6\% reported heifer breedings in 2003 and those herds accounted for 58\% of all lactat-
Table 2. Overall frequency of confirmation codes in initial data

\begin{tabular}{lcr}
\hline $\begin{array}{l}\text { Confirmation } \\
\text { code }^{1}\end{array}$ & Frequency \\
\hline 1 & 350,226 & \multicolumn{1}{c}{37.6} \\
2 & 35,981 & 3.9 \\
3 & 22,544 & 2.4 \\
4 & 142,422 & 15.3 \\
5 & 327,296 & 35.2 \\
6 & 52,089 & 5.6 \\
\hline
\end{tabular}

${ }^{1}$ Codes: 1 = confirmed open, another reproductive event (breeding, heat, pregnancy check indicating open) occurred after breeding; 2 = confirmed open, calving date indicated breeding did not result in calving; 3 = confirmed open, adequate time elapsed with no reported calving and herd still on test; $4=$ confirmed pregnant by pregnancy exam; 5 = confirmed pregnant by subsequent calving; $6=$ unknown .

ing cows on test with those 2 processing centers. For inclusion in the AIPL database, the only required pieces of information for a reported breeding are the animal identification and date of the breeding; service sire is not required in order for the reported breeding to be kept. Nevertheless, $90 \%$ of all services reported had a recorded service sire.

The overall, arithmetic mean CR by breed is also given in Table 1, for breeds with at least 100 matings. Milking Shorthorn and crossbred heifers had the highest mean CR (59.3 and 59.2\%, respectively) followed by Holsteins (56.3\%). Linebacks, with only 462 matings, had the lowest mean CR (38.7\%). United States Jersey cows average about 17 fewer DO than US Holstein cows (AIPL, 2005). Thus, in contrast to cow fertility, Holstein heifers actually had better fertility than Jersey heifers. Standard deviations of CR are also given in Table 1 and were generally around 50\% for all breeds. A standard deviation of $50 \%$ (variance of $25 \%$ ) is expected for a Bernoulli random variable with a mean (probability of success) of 0.5 .

Confirmation codes and their frequencies are given in Table 2. Only $5.6 \%$ of all matings had an unknown status. Another concern with breeding data is whether all breedings are reported by the producer. Confirmation code 2 (last breeding date and calving date disagree, indicating that a different breeding actually led to the calving) provides some indication of the extent of underreporting. The relative frequency of $3.9 \%$ is probably an upper-end estimate, though, because some of the discrepancies between last reported breeding date and calving dates could have simply been recording errors. Furthermore, although known abortions were not counted in confirmation code 2 , unreported abortions may have inflated the frequency of code 2 somewhat as well. In general, for herds that do report heifer breedings, reporting appears to be reasonably complete.

Table 2 also provides the means to calculate a rough estimate of the culling rate for heifers that had at least 
Table 3. Linear model mean squares (MS), logistic model relative $\chi^{2}$ values, and $P$-values for both models ${ }^{1}$

\begin{tabular}{|c|c|c|c|c|c|}
\hline \multirow[b]{2}{*}{ Source } & \multirow[b]{2}{*}{$\mathrm{df}$} & \multicolumn{2}{|c|}{ Linear model } & \multicolumn{2}{|c|}{ Logistic model } \\
\hline & & MS & $P>F$ & Relative $\chi^{2}$ & $P>\chi^{2}$ \\
\hline AI year & 2 & 119.37 & $<0.0001$ & 508.59 & $<0.0001$ \\
\hline Heifer age & 8 & 9.64 & $<0.0001$ & 40.71 & $<0.0001$ \\
\hline AI month & 11 & 5.21 & $<0.0001$ & 22.11 & $<0.0001$ \\
\hline Herd & 2,667 & 1.67 & $<0.0001$ & 6.94 & $<0.0001$ \\
\hline Stud & 21 & 1.37 & $<0.0001$ & 5.84 & $<0.0001$ \\
\hline Service sire age & 3 & 1.35 & 0.0007 & 5.63 & 0.0007 \\
\hline Service sire age $\times$ Service sire inbreeding & 9 & 1.28 & $<0.0001$ & 5.37 & $<0.0001$ \\
\hline Heifer inbreeding & 4 & 1.23 & 0.0004 & 5.21 & 0.0003 \\
\hline Service sire inbreeding & 3 & 1.12 & 0.0027 & 4.72 & 0.0027 \\
\hline Mating inbreeding & 4 & 0.91 & 0.0040 & 3.84 & 0.0040 \\
\hline
\end{tabular}

${ }^{1}$ Based on all data, including unconfirmed matings.

1 breeding. The frequencies for codes 2,3 , and 5 are not only counts on number of breedings but also number of heifers in those categories, because each heifer could be coded only once with a 2,3 , or 5 . Furthermore, the sum of the frequencies for codes 2,3 , and 5 represents the number of heifers that had been bred long enough to have calved. Thus, a rough estimate of the percentage of heifers with at least 1 breeding that were culled is $100 \times[22,544 /(35,981+22,544+327,296)]=6 \%$. This estimate would include not only intentional culling but also any death loss that occurred. The $6 \%$ estimated heifer loss could be an overestimate if the heifers were culled very shortly after calving, and thus never had their calving recorded or, for whatever reason (e.g., heifer sold into a herd not on test), the producer stopped reporting breedings of these heifers.

One last aspect investigated was the occurrence of breedings to pregnant heifers. An AI service was considered a breeding to a pregnant heifer if 1 ) the expected calving date, given the breeding date, was more than $15 \mathrm{~d}$ after the actual calving date, and 2) there was a previous breeding date that matched the calving date within $10 \mathrm{~d}$. Lactations known to be initiated by abortions were excluded from this analysis; the second requirement was to protect against unreported abortions. The percentage of heifers with a breeding after pregnancy was $1.67 \%$.

\section{Factors Affecting CR}

Table 3 presents the SAS Type III mean squares and $\chi^{2}$ values for the linear and logistic models, respectively, as well as $P$-values for both models. Because $\chi^{2}$ values tend to be larger for factors with a large number of levels, simply because there are more terms in the summation, relative $\chi^{2}$ values were calculated by dividing actual $\chi^{2}$ values by their degrees of freedom to permit comparison to linear model mean squares. There was very little difference in results between the linear and logistic models. Effects in Table 3 are sorted by their level of importance as indicated by the mean square. Factors ranked the same with both the linear and logistic models and $P$-values for the 2 models were quite similar. Furthermore, least squares means (Tables 4 through 6 ) were nearly identical for the 2 models. It is perhaps worthwhile to note that this similarity of results between the linear and logistic models will not necessarily hold in general for all analyses involving binary traits. It is well known that a binomial distribution is approximated by the normal distribution and, most importantly, that this approximation improves as sample size increases and as the probability of success approaches 0.5 (Collett, 2003). Thus, with smaller sample (subclass) sizes or for binary traits with means closer to 0 or 1 , the difference between logistic and linear models could be larger than that observed in this study. Given, however, essentially no difference in the results between the 2 models in this research, further discussion will focus exclusively on linear model results.

Of the factors listed in Table 3, AI year had the largest mean square. The magnitude of its effect, however, was due to inclusion of data from 2005 , in which the majority of unconfirmed matings occurred. When heifers with unconfirmed matings were excluded, the mean square for AI year was only 15, in contrast to 119 when unconfirmed matings were included. Age of the heifer at breeding was the next most important main effect, in terms of magnitude of impact on CR, followed by month of breeding, herd, stud, age of service sire, and then inbreeding. Among the inbreeding coefficients considered, inbreeding in the heifer had the largest impact on $\mathrm{CR}$ followed by inbreeding in the service sire, and then the inbreeding of the mating (potential embryo).

Tables 4 through 6 present the mean CR for the 2 linear model analyses: confirmed matings only and all matings. The overall arithmetic mean, after edits, was largely insensitive to inclusion or exclusion of unconfirmed matings. The arithmetic mean with confirmed 
Table 4. Least squares means for linear and logistic models for year of AI, AI month, age of heifer at breeding, and service sire age at breeding

\begin{tabular}{|c|c|c|c|c|c|}
\hline \multirow[b]{2}{*}{ Factor } & \multirow[b]{2}{*}{ Level } & \multirow{2}{*}{$\begin{array}{l}\text { No. of } \\
\text { matings }\end{array}$} & \multicolumn{2}{|c|}{ Linear model } & \multirow{2}{*}{$\begin{array}{c}\begin{array}{c}\text { Logistic } \\
\text { model }\end{array} \\
\text { All data }\end{array}$} \\
\hline & & & Conf. only ${ }^{3}$ & All data & \\
\hline \multirow[t]{3}{*}{ AI year } & 2003 & 145,935 & $50.6 \pm 0.82$ & 51.4 & 51.5 \\
\hline & 2004 & 233,270 & $50.5 \pm 0.81$ & 51.1 & 51.2 \\
\hline & 2005 & 158,733 & $52.6 \pm 0.82$ & 56.5 & 56.9 \\
\hline \multirow[t]{12}{*}{ AI month } & January & 42,714 & $51.5 \pm 0.85$ & 52.0 & 52.1 \\
\hline & February & 42,501 & $51.6 \pm 0.85$ & 52.8 & 53.0 \\
\hline & March & 53,192 & $51.7 \pm 0.84$ & 53.1 & 53.3 \\
\hline & April & 50,239 & $53.2 \pm 0.84$ & 54.6 & 54.9 \\
\hline & May & 51,109 & $51.9 \pm 0.84$ & 53.9 & 54.1 \\
\hline & June & 49,861 & $51.7 \pm 0.84$ & 54.2 & 54.5 \\
\hline & July & 48,371 & $50.1 \pm 0.84$ & 53.4 & 53.6 \\
\hline & August & 47,058 & $48.4 \pm 0.84$ & 51.0 & 51.0 \\
\hline & September & 33,640 & $50.1 \pm 0.85$ & 51.8 & 51.9 \\
\hline & October & 37,430 & $50.7 \pm 0.85$ & 52.5 & 52.6 \\
\hline & November & 37,562 & $51.5 \pm 0.85$ & 53.2 & 53.4 \\
\hline & December & 44,261 & $52.5 \pm 0.85$ & 54.0 & 54.2 \\
\hline \multirow[t]{9}{*}{ Heifer age (mo) } & 11 to 12 & 6,983 & $52.8 \pm 1.03$ & 53.3 & 53.5 \\
\hline & 13 to 14 & 114,121 & $55.7 \pm 0.82$ & 56.3 & 56.5 \\
\hline & 15 to 16 & 207,801 & $55.8 \pm 0.80$ & 56.5 & 56.8 \\
\hline & 17 to 18 & 115,394 & $54.0 \pm 0.80$ & 54.7 & 55.0 \\
\hline & 19 to 20 & 51,264 & $52.7 \pm 0.82$ & 53.8 & 54.0 \\
\hline & 21 to 22 & 23,584 & $50.7 \pm 0.86$ & 52.3 & 52.4 \\
\hline & 23 to 24 & 11,368 & $49.5 \pm 0.93$ & 51.3 & 51.4 \\
\hline & 25 to 26 & 5,669 & $47.6 \pm 1.06$ & 51.1 & 51.1 \\
\hline & 26 to 27 & 1,754 & $42.4 \pm 1.49$ & 48.1 & 48.0 \\
\hline \multirow{4}{*}{ Service sire age $(\mathrm{yr})$} & $\leq 1.5$ & 8,659 & $48.9 \pm 1.44$ & 50.8 & 50.9 \\
\hline & 1.5 to 3 & 12,352 & $50.5 \pm 1.06$ & 52.0 & 52.1 \\
\hline & 3 to 5 & 18,679 & $53.5 \pm 0.97$ & 55.3 & 55.6 \\
\hline & $>5$ & 498,248 & $52.1 \pm 0.71$ & 54.0 & 54.2 \\
\hline
\end{tabular}

${ }^{1}$ All data, including unconfirmed matings.

${ }^{2}$ AI year 2003 only included March through December and 2005 only January through August.

${ }^{3}$ Least squares means using only matings with confirmed (conf.) outcomes.

matings only was $56.5 \%$ and with unconfirmed matings included it was $57.1 \%$. The general effect of including unconfirmed matings on least squares means was to raise subclass means by about 1 to $4 \%$ but differences between means were generally the same for the 2 different analyses.

The mean CR for the year 2005 was $56.5 \%$ (Table 4) when all data was used vs. $52.6 \%$ when only confirmed matings were used, illustrating the reason the mean square dropped from 119 (all data, Table 3) to only 15 when heifers with unconfirmed matings were excluded. However, even when heifers with unconfirmed matings were excluded, AI year still had the largest mean square and the mean for 2005 was still about $2 \%$ higher than the mean for the other years. The mean for 2005 was still biased upward, even when heifers with unconfirmed matings were excluded, because only the easiest to breed (highest CR) heifers from 2005 would have been included for that year in the "confirmed only" analyses. When only the last (unconfirmed) matings were excluded, in contrast to deleting the entire heifer, the year means were $50.3 \%$ (2003), $49.1 \%$ (2004), and $47.8 \%$
(2005); editing in this manner caused a downward bias in the AI year means because all of the failed matings, for heifers with unconfirmed breedings, were included but none of the potentially successful matings were included. Thus, inclusion of the 2005 breedings biased the estimation of year effects; excluding only unconfirmed matings causes a downward bias whereas excluding the entire heifer, if her last mating was unconfirmed, causes an upward bias in the year effect. Nonetheless, the 2005 data were included in this research because it illustrates a difficulty or concern in the analysis of breeding data when pregnancy confirmation information is incomplete. If interest were solely in quantifying year-to-year variation, simply excluding the most recent year of breedings would suffice to eliminate most biases due to unconfirmed matings because most animals included would then have time to be confirmed. However, for the purpose of prediction of service sire effects or breeding values for female CR, excluding the most recent year of data is undesirable because it implies a substantial loss of information, especially for young bulls. When the interest is in the prediction of 
Table 5. Least squares means for studs for linear and logistic models, sorted by estimates from the linear model using confirmed (Conf.) matings only

\begin{tabular}{|c|c|c|c|c|}
\hline \multirow[b]{2}{*}{ Stud $^{1}$} & \multirow{2}{*}{$\begin{array}{l}\text { No. of } \\
\text { matings }\end{array}$} & \multicolumn{2}{|c|}{ Linear model } & \multirow{2}{*}{$\begin{array}{c}\begin{array}{c}\text { Logistic } \\
\text { model }\end{array} \\
\text { All data }\end{array}$} \\
\hline & & Conf. only $\pm \mathrm{SE}$ & All data & \\
\hline A & 1,587 & $44.0 \pm 1.57$ & 46.2 & 46.1 \\
\hline B & 270 & $46.7 \pm 3.28$ & 49.7 & 49.6 \\
\hline $\mathrm{C}$ & 917 & $46.8 \pm 1.97$ & 48.4 & 48.4 \\
\hline $\mathrm{D}$ & 435 & $50.0 \pm 2.77$ & 52.7 & 52.9 \\
\hline $\mathrm{E}$ & 678 & $50.1 \pm 2.13$ & 51.0 & 51.0 \\
\hline $\mathrm{F}$ & $>20,000$ & $50.3 \pm * 3$ & 52.2 & 52.3 \\
\hline G & 2,500 & $50.8 \pm 1.29$ & 52.6 & 52.7 \\
\hline $\mathrm{H}$ & $>20,000$ & $51.1 \pm *$ & 52.8 & 52.9 \\
\hline I & 17,581 & $51.5 \pm 0.86$ & 53.2 & 53.3 \\
\hline $\mathrm{J}$ & 7,246 & $51.5 \pm 0.99$ & 53.1 & 53.2 \\
\hline $\mathrm{K}$ & 2,452 & $52.0 \pm 1.34$ & 54.4 & 54.7 \\
\hline $\mathrm{L}$ & $>20,000$ & $52.1 \pm *$ & 53.7 & 53.9 \\
\hline $\mathrm{M}$ & $>20,000$ & $52.5 \pm *$ & 54.1 & 54.3 \\
\hline $\mathrm{N}$ & $>20,000$ & $52.5 \pm *$ & 54.2 & 54.4 \\
\hline $\mathrm{O}$ & 2,330 & $53.0 \pm 1.33$ & 54.4 & 54.6 \\
\hline $\mathrm{P}$ & $>20,000$ & $53.1 \pm *$ & 54.8 & 55.0 \\
\hline Q & 981 & $53.1 \pm 1.84$ & 54.3 & 54.5 \\
\hline $\mathrm{R}$ & 260 & $53.2 \pm 3.41$ & 56.3 & 56.7 \\
\hline $\mathrm{S}$ & 3,674 & $53.2 \pm 1.15$ & 54.5 & 54.7 \\
\hline $\mathrm{T}$ & 582 & $53.9 \pm 2.35$ & 55.0 & 55.2 \\
\hline $\mathrm{U}$ & 2,402 & $54.7 \pm 1.32$ & 56.3 & 56.7 \\
\hline
\end{tabular}

${ }^{1}$ Arbitrary stud identification.

${ }^{2}$ All data, including unconfirmed matings.

$3 *=0.77 \leq \mathrm{SE} \leq 0.84$.

random effects, though, the effect of AI year will simply be a nuisance variable. The promising and important implication of these results, then, is that the effect of unconfirmed matings will be largely partitioned into the fixed effects (nuisance variables) and out of the random effects of interest.
In regard to year effects per se, little difference was observed in the means for years 2003 and 2004 (Table 4 ), indicating only a small amount of variation due to mating year. Nonetheless, a data set that includes more years than were available in this study would be useful for ascertaining year-to-year variation in heifer CR.

Month effects (Table 4) were somewhat sporadic in that there was not a clear, definitive pattern across months. April had the highest CR and August the lowest, but July, for example, had a higher CR than March, at least based on all breedings. To further assist the interpretation of month effects, four 3-mo seasons were defined: January, February, March (season 1); April, May, June (season 2); July, August, September (season 3); and October, November, December (season 4) and means across months were calculated for each season. Season means, based on all data, were 52.6, 54.2, 52.1, and $53.2 \%$ for seasons 1 through 4 , respectively. The spring season (season 2) had the highest CR followed by fall (season 4) whereas the summer season (season 3) had the lowest CR. The season ranking was essentially the same using confirmed matings only, except that there was no difference between seasons 1 and 4 (the middle ranking seasons). The most notable result, though, was that differences among seasons were relatively small; the overall range amongst month means was only $3.6 \%$ based on all data and $4.8 \%$ with confirmed matings only. Although the mean for the summer season was lowest, it was only $0.5 \%$ lower than season 1 . Month effects for heifer fertility were in contrast to those that have been reported for cows. Weigel (2004), for example, found a range of $8.4 \%$ in month means for cow CR, with June, July, and August having

Table 6. Least squares means for heifer, mating (potential embryo), and service sire inbreeding for linear and logistic models

\begin{tabular}{|c|c|c|c|c|c|}
\hline \multirow[b]{2}{*}{ Factor } & \multirow{2}{*}{$\begin{array}{l}\text { Level of } \\
\text { inbreeding } \\
(\%)\end{array}$} & \multirow{2}{*}{$\begin{array}{l}\text { No. of } \\
\text { matings }{ }^{1}\end{array}$} & \multicolumn{2}{|c|}{ Linear model } & \multirow{2}{*}{$\begin{array}{c}\begin{array}{c}\text { Logistic } \\
\text { model }\end{array} \\
\text { All data }\end{array}$} \\
\hline & & & Conf. only $\pm \mathrm{SE}^{2}$ & All data & \\
\hline \multirow[t]{5}{*}{ Heifer inbreeding } & 0 to 3 & 25,762 & $53.1 \pm 0.70$ & 54.9 & 55.2 \\
\hline & 3 to 6 & 427,258 & $52.4 \pm 0.63$ & 54.2 & 54.4 \\
\hline & 6 to 10 & 78,880 & $51.8 \pm 0.65$ & 53.6 & 53.8 \\
\hline & 10 to 20 & 5,615 & $51.2 \pm 0.92$ & 53.2 & 53.4 \\
\hline & $>20$ & 423 & $47.7 \pm 2.55$ & 49.3 & 49.3 \\
\hline \multirow[t]{5}{*}{ Mating inbreeding } & 0 to 3 & 7,335 & $52.5 \pm 0.95$ & 54.2 & 54.4 \\
\hline & 3 to 6 & 395,509 & $51.9 \pm 0.75$ & 53.7 & 53.9 \\
\hline & 6 to 10 & 124,108 & $51.4 \pm 0.76$ & 53.2 & 53.4 \\
\hline & 10 to 20 & 9,551 & $51.7 \pm 0.91$ & 53.4 & 53.5 \\
\hline & $>20$ & 1,435 & $48.6 \pm 1.54$ & 50.7 & 50.7 \\
\hline \multirow[t]{4}{*}{ Service sire inbreeding } & 0 to 3 & 67,285 & $53.0 \pm 1.15$ & 55.2 & 55.4 \\
\hline & 3 to 6 & 343,352 & $50.8 \pm 0.75$ & 52.8 & 52.9 \\
\hline & 6 to 10 & 105,420 & $49.7 \pm 0.80$ & 51.7 & 51.8 \\
\hline & 10 to 15 & 21,881 & $51.4 \pm 1.44$ & 52.5 & 52.7 \\
\hline
\end{tabular}

${ }^{1}$ All data, including unconfirmed matings.

${ }^{2}$ Least squares means using only matings with confirmed (conf.) outcomes. 
the lowest CR and January and February having the highest. The summer season clearly has less adverse effects on heifer CR than on CR for lactating cows.

Much of the published research on factors affecting heifer fertility has been based only on single herds for a single year. Nonetheless, these studies provide some support and explanation for the general result of lower season effects for heifer CR than for cow CR. Donovan et al. (2003) found, using a single Florida herd, that CR was 23\% lower for heifers during the summer months than during winter. Badinga et al. (1985), however, also used a single Florida herd and reported only slightly lower heifer CR in summer months, after adjusting for climatological factors including air temperature, solar radiation, and rainfall (i.e., month effects were not due to climatic differences). Badinga et al. (1985) also found that, in contrast to cow fertility, heifer fertility actually improved with increasing air temperature until temperatures reached $35^{\circ} \mathrm{C}\left(95^{\circ} \mathrm{F}\right)$. Sartori et al. (2002) reported that the body temperature of heifers increased less than that of cows with increasing ambient temperature and also reported a 100\% fertilization rate for heifers during summer months; embryo quality for heifers in the summer was the same as that for dry cows in winter months and better than that for lactating cows in winter. Ron et al. (1984) reported highest heifer CR in February (67\%) but CR in July (65.4\%) was only slightly lower and July CR was higher than the January CR of 64.6\%. Rankin et al. (1992), using the University of Illinois research herd, also reported better heifer CR in summer months than in winter months, although their best CR was in the fall season. Salisbury et al. (1978) speculated that shorter day length might reduce fertility. Thus, results from previous research on month effects for heifer fertility vary somewhat but generally indicate 1) much smaller effects for heifers than for cows, and 2) that summer breeding is much less adverse for heifers than for cows; both factors are consistent with the results from this study.

Breeding heifers at 15 to 16 mo of age maximized CR (Table 4). Conception rate was lower not only for breedings at $<15$ mo of age but for breedings $>16$ mo of age as well and especially for those $>26$ mo of age. In fact, the most pronounced effect of heifer age was a 5 to $10 \%$ lower CR for heifers bred at 26 to $27 \mathrm{mo}$ of age. To ensure that the effect of older ages was not due to only poorer fertility heifers being bred at older ages, age effects were also estimated using CR on first service only and results were similar to those presented in Table 4. Donovan et al. (2003) is one of the few studies to consider the effect of heifer age on CR and they reported no effect of age but used only 2 age categories ( $\geq$ median and $<$ median age). The cause of the lower $\mathrm{CR}$ for breedings at older ages could not be ascertained with the data available in this research. Perhaps these lower means at older ages are not age effects per se but rather resulted from breedings to late-maturing heifers, heifers that were subfertile for other reasons, or that the older heifers may have become overconditioned.

Service sire age (Table 4) also showed an intermediate optimum with the best CR occurring for breedings to bulls between the ages of 3 to 5 yr. Similar results were also obtained for service sire age using CR on first service only. Thus, the effect of young bulls was not due to young (perhaps lower priced) bulls being used on less fertile heifers that did not conceive during initial matings. In regard to bull age, it is important to note that date of collection is not reported to AIPL. Bull "age," then, was the age of the bull at the time of mating, not age at the time of collection. Nonetheless, although notable exceptions certainly occur, the amount of time between collection and usage is presumably uniform across bulls because an AI bull would not remain in service unless his semen was being used. Furthermore, for some applications the only relevant issue is whether a variable (service sire age at mating in this case) is related to $\mathrm{CR}$; what exactly the variable is measuring can be irrelevant to a large extent. Kuhn et al. (2004), for example, utilized service sire age in a phenotypic predictor of bull fertility. In such an application, interest is solely in whether the variable is related to CR. The significance $(P<0.0027$, Table 3$)$ of the service sire age term in this research supports the use of this variable in formulation of predictions of service sire fertility. Less popular bulls will likely have a greater lag between collection date and date of use than more popular bulls due to banking of semen. Further research could examine whether the effect of bull age at mating varies according to some measure of bull popularity (e.g., number of daughters or number of breedings).

In regard to service sire age effects estimated with field data, it should be acknowledged that the increase in CR across the first 3 bull age groups (Table 4) could be confounded with culling if culling on observed bull CR or semen quality occurred over those age groups. Conversely, field data may underestimate the true (biological) effects of service sire age on CR if sperm concentration is increased with increasing age to offset losses in compensable semen characteristics. Although there is some potential for confounding of service sire age effects with other factors in field data, bull age effects in Table 4 do not reflect genetic trend. Preliminary estimates using cow breedings indicate that the heritability of AI service sire fertility is essentially zero. Furthermore, the differences between service sire age groups would be linear (decreasing with increasing age) if age differences were reflecting favorable genetic trend 
and this was not at all the pattern observed; CR increased up until 3 to $5 \mathrm{yr}$ of age and then declined (Table 4).

A number of older studies investigated the effect of bull age on bull fertility, several of which were reviewed by Salisbury et al. (1978). Tanabe and Salisbury (1946) reported peak fertility at $2 \mathrm{yr}$ of age for bulls, but Bishop (1970) found peak fertility at slightly higher ages of 3 to 4 yr. Hahn et al. (1969) found that a number of sperm characteristics (e.g., motility after freezing and thawing, percentage of normal sperm) were better in younger bulls than older bulls. These results generally support the findings of this research that, in turn, provides some confirmation that service sire age at time of mating is a reasonable variable for studying bull age effects on AI fertility, despite potential confounding with other factors.

Stud means are presented in Table 5. Although the range in stud means was considerable (44.0 to 54.7\%, confirmed matings only), most studs were in the range of about 50 to $53 \%$. The studs listed in Table 5 included every organization with a stud code assigned by the National Association of Animal Breeders. However, only 6 of the studs listed in Table 5 (5 US, 1 Canadian) corresponded to major AI companies that service the entire United States. The other stud codes were smaller operations or custom collection agencies that may collect and process semen for individual herds. Thus, although a wide range of $\mathrm{CR}$ were observed among all stud codes, the 5 major US studs differed by a maximum of only $2.8 \%$ based on confirmed matings only. Certainly, the exact cause of stud differences cannot be ascertained with field data alone. A wide range of factors may contribute to stud differences, including variations in semen collection and processing as well as management of the bulls themselves. Some AI organizations have argued that some companies provide a greater amount of (professional) AI technician service than others and that this contributes to observed stud differences. Herds that use semen from only one stud could not contribute to such an effect, if it exists, because the (professional) technician effect would become part of the herd mean (effect). In order for technician to contribute to observed stud differences, herds that use semen from multiple companies would have to routinely use more skilled technicians for semen from one particular stud and a given stud would have to be routinely favored across herds. Whether this occurs or is likely to occur could not be ascertained from the current data because technician (inseminator) information is not currently being supplied in Format 5.

Mean CR for heifer, mating, and service sire inbreeding groups are presented in Table 6. Falconer (1989) reviewed results from numerous inbreeding studies
Table 7. Service sire age by service sire inbreeding subclass means $( \pm \mathrm{SE})^{1}$

\begin{tabular}{lllll}
\hline \multirow{2}{*}{$\begin{array}{l}\text { Inbreeding } \\
\%\end{array}$} & \multicolumn{5}{c}{ Age $(\mathrm{yr})$} \\
\cline { 2 - 6 } & $\leq 1.5$ & 1.5 to 3 & 3 to 5 & $>5$ \\
\hline 0 to 3 & $58.5 \pm 2.86$ & $57.2 \pm 1.63$ & $51.0 \pm 1.75$ & $53.9 \pm 0.70$ \\
3 to 6 & $49.8 \pm 0.97$ & $51.5 \pm 0.90$ & $55.6 \pm 0.82$ & $54.2 \pm 0.69$ \\
6 to 10 & $49.7 \pm 1.23$ & $48.3 \pm 1.09$ & $55.3 \pm 0.98$ & $53.7 \pm 0.70$ \\
10 to 15 & $45.4 \pm 3.70$ & $50.9 \pm 2.57$ & $59.4 \pm 2.02$ & $54.3 \pm 0.77$ \\
\hline
\end{tabular}

${ }^{1}$ From the linear model, based on all data including unconfirmed matings.

from a number of species and subsequently stated, "The most striking observed consequence of inbreeding is the reduction of the mean phenotypic value shown by characters connected with reproductive capacity. . .." Given that inbreeding generally reduces fertility, both heifer and embryo inbreeding effects behaved as expected with CR decreasing as inbreeding increased. The magnitude of the effect, however, was perhaps less than expected. Only at the highest level of heifer and embryo inbreeding did CR decrease appreciably. There was, for example, only a $1.2 \%$ difference in CR for heifers with 3 to $6 \%$ inbreeding vs. heifers with 10 to $20 \%$ inbreeding. Cassell et al. (2003) reported even smaller inbreeding effects for cows and embryos from cows. The rather small differences in CR among the first 3 or 4 levels of heifer and embryo (Table 6) inbreeding should not be taken as an indication to ignore inbreeding or that increasing relationships among animals in the population will be without consequence. One should note that, although the highest levels of inbreeding ( $>10$ or $>20 \%$ ) are currently at low frequency, when those high levels do occur there is clearly a reduction in fertility. These results support efforts to minimize inbreeding and attempts to maintain as broad of a genetic base in the population as possible.

Although the inbreeding effects for heifers and embryos were in the expected directions, the main effect of inbreeding on the fertility of service sires (Table 6) was peculiar. Conception rate did decrease with increasing inbreeding for the first 3 categories but CR was higher for the most highly inbred bulls (category 4) than for bulls in categories 2 and 3 . The reason for this can be seen in Table 7, which shows an interaction of service sire inbreeding with service sire age. Considering only matings in which the service sire was less than $1.5 \mathrm{yr}$ of age, the most inbred bulls did have the lowest CR, as expected. It was only at older ages where the most highly inbred bulls had CR higher than less inbred bulls. Thus, the highly inbred (and lower fertility) bulls were apparently culled more intensely on fertility based on field data, observed after initial matings. It may also be that inbreeding affects compensable 
Table 8. Distribution of herd mean conception rates (CR), using least squares means from a linear model

\begin{tabular}{lccc}
\hline $\begin{array}{l}\text { Herd } \\
\text { mean CR } \\
(\%)\end{array}$ & Frequency & $\%$ & $\begin{array}{l}\text { Cumulative } \\
\%\end{array}$ \\
\hline$\leq 20$ & 6 & 0.2 & 0.22 \\
20 to 30 & 25 & 0.9 & 1.16 \\
30 to 40 & 213 & 8.0 & 9.15 \\
40 to 50 & 704 & 26.4 & 35.53 \\
50 to 60 & 1,070 & 40.1 & 75.64 \\
60 to 70 & 579 & 21.7 & 97.34 \\
70 to 80 & 70 & 2.6 & 99.96 \\
$>80$ & 1 & 0.0 & 100 \\
\hline
\end{tabular}

sperm characteristics and that sperm concentration was increased in the most highly inbred bulls, after observing below average fertility on these bulls in field matings. One implication of this result is that age of service sire needs to be taken into account when considering effects of inbreeding on AI bull fertility. Maltecca et al. (2006), for example, compared the CR of proven purebred Holstein bulls to Holstein $\times$ Jersey crossbred bulls and concluded there was no difference between the 2 groups of bulls. Although the comparison made by Maltecca et al. (2006) was certainly of practical interest, results in Table 7 show that some care has to be taken in the interpretation of such comparisons because culling or compensable semen characteristics may obscure differences. The interaction of service sire inbreeding with service sire age also has implications for phenotypic prediction of service sire fertility from field data. Kuhn et al. (2004) utilized service sire inbreeding in a predictor of bull CR. These results suggest, however, that allowing the service sire inbreeding effect to vary according to age would improve prediction.

The distribution of herd means from the linear model is given in Table 8. The majority of herds fell in the range of 30 to $70 \%$, and $66 \%$ of all herds had mean CR between 40 and $60 \%$. The distribution of herd means suggests that if a herd's heifer CR is below $40 \%$ (about $9 \%$ of all herds) an appraisal of heifer management would likely be beneficial. Herd CR was essentially unrelated to herd size (number of milking cows). The linear regression of herd CR on herd size was only -0.0024 $(P<0.06)$ and the quadratic regression was essentially zero and nonsignificant. The sample correlation between herd size and herd CR was only -0.025 . Tenhagen et al. (2004) reported lower CR with estrus synchronization programs. Unfortunately, synchronization events are not currently being reported to AIPL, so determination could not be made as to whether this factor might account for some of the lower herd means.

Table 9 contains mean heifer CR for parent average DPR groups. Heifer CR increased with increasing parent average DPR $(P<0.0001)$, indicating that selection on US DPR evaluations will not only improve DO in cows but also CR in heifers. Results in Table 9 for the effect of service sire breed are for when the indicated breed of sire is mated to purebred Holstein heifers. Holstein heifers actually conceived better to Holstein bulls than to Brown Swiss or Jersey bulls, although the other breeds combined did have a higher mean than Holstein service sires. Mean CR based on all services and on first service only are presented in Table 9 for service sire breed because some farmers might resort to using other breeds only after the heifer has failed to conceive on several previous matings, which would bias the breed comparisons in favor of Holstein bulls. However, the same general pattern of breed differences was observed using records from first service only $(P<$ 0.003), although the difference between Holstein and the "all other breeds" category was smaller than for all services. Recent literature, both popular press and scientific, has reflected an increased interest in crossbreeding for dairy cattle. Although the purpose of this paper was certainly not to evaluate the merits or demerits of crossbreeding, one implication of these results is that even if crossbred animals are economically superior to their purebred counterparts, some cost in CR will be incurred for at least the initial matings when Jersey or Brown Swiss bulls are used on Holstein females.

Table 9. Mean conception rates (CR) for parent average daughter pregnancy rate (DPR) groups and service sire breeds

\begin{tabular}{|c|c|c|c|c|}
\hline \multicolumn{2}{|c|}{ Parent average $\mathrm{DPR}^{1}$} & \multicolumn{3}{|c|}{ Service sire breed ${ }^{2}$} \\
\hline Parent DPR & Mean CR (\%) & Breed & All services & First service \\
\hline$\leq-2$ & $52.3 \pm 0.79$ & Brown Swiss & $52.0 \pm 1.94$ & $50.3 \pm 2.63$ \\
\hline-2 to 0 & $52.5 \pm 0.80$ & Holstein & $55.4 \pm 0.53$ & $55.2 \pm 0.72$ \\
\hline 0 to 2 & $53.6 \pm 0.78$ & Jersey & $52.6 \pm 0.79$ & $52.8 \pm 1.04$ \\
\hline$>2$ & $55.4 \pm 0.83$ & Other $^{3}$ & $61.0 \pm 2.10$ & $57.9 \pm 2.72$ \\
\hline
\end{tabular}


Table 10. Number of matings and conception rate $(\mathrm{CR})$ by service number

\begin{tabular}{lrl}
\hline $\begin{array}{l}\text { Service } \\
\text { number }\end{array}$ & $\begin{array}{l}\text { No. of } \\
\text { matings }\end{array}$ & CR (\%) \\
\hline 1 & 341,139 & 53.3 \\
2 & 109,743 & 52.9 \\
3 & 36,469 & 49.7 \\
4 & 13,433 & 47.9 \\
5 & 5,119 & 43.8 \\
6 & 2,064 & 39.1 \\
7 & 907 & 32.7 \\
\hline
\end{tabular}

Conception rate by service number is given in Table 10. As expected, CR decreased with increasing service number because only heifers that are more difficult to breed have breedings at higher service numbers. By fifth service, CR was nearly $10 \%$ lower than on first service and dropped to 39.1 and $32.7 \%$ for sixth and seventh services, respectively. Thus, although CR is still reasonable on fifth service, if a heifer has not conceived after 4 breedings it would appear prudent to ascertain the health and reproductive status of the heifer. If conception has not occurred by the fifth service, culling may be warranted because CR drops below $40 \%$ after the fifth service.

\section{Parameter Estimates}

Parameter estimates are presented in Table 11. Heritability of heifer CR is quite low. The linear model estimate of heritability for CR on first service was $0.5 \%$ whereas the threshold model estimate was $1.0 \%$. Higher heritabilities on the underlying scale (threshold model) than on the observed scale (linear model) have been commonly reported for cow fertility. Weigel and Rekaya (2000), for example, reported heritability estimates for nonreturn rate at $90 \mathrm{~d}$ in cows of $1.5 \%$ from a linear model and $1.8 \%$ from a threshold model. Andersen-Ranberg et al. (2005) reported even larger differences for nonreturn rate at $56 \mathrm{~d}$ in cows; their linear model estimate of heritability was $1.2 \%$, and the thresh- old model estimate was 2.7\%. Weller and Ron (1992) obtained $2.4 \%$ heritability for heifer CR from a linear model vs. $3.5 \%$ heritability from a threshold model.

Heritability was greater for first service only than for all services in both the linear and threshold models. Presumably, environmental factors play a relatively larger role in repeated services than for first service in heifers. Including unconfirmed matings for estimation of heritability had no effect on estimates from the linear model. Thus, at least in heifers, unconfirmed matings appear to affect subclass means for fixed effects somewhat, with little or no disturbance in ratios of variances.

Although all are low, literature estimates of heritability for heifer CR are variable. Ron et al. (1984) reported a linear model estimate of $0.6 \%$ for heifer CR on all services in Israeli Holsteins, which is similar to the $0.5 \%$ estimated in this study. The estimate of heritability for cow CR from Ron et al. (1984) was 1.6\%, supporting the hypothesis of lower heritability for heifer CR than for cow CR. In contrast, Weller and Ron (1992) reported higher heritabilities for Israeli Holstein heifers (2.4\% linear model, $3.5 \%$ threshold model) than for cows (1.4\% linear model, $2.2 \%$ threshold model). Andersen-Ranberg et al. (2003) reported linear model estimates of 1.2 to $1.4 \%$ for 56 -d nonreturn rate in Norwegian dairy heifers.

The genetic correlation of heifer and cow CR on first service was 0.39 . This is consistent with the linear model estimate of 0.27 from Ron et al. (1984) for all services in Israeli Holstein heifers. Raheja et al. (1989) estimated a genetic correlation of only 0.01 for number of services per conception in heifers and cows. Oltenacu et al. (1991), however, reported a genetic correlation between heifer and cow first-service CR of 0.59 for Swedish Red and Whites. Although it is certainly possible that the genetic correlation is higher in Swedish Red and Whites than in US Holsteins, Oltenacu et al. (1991) acknowledged that the data selection imposed in their study could have caused a bias in their estimates. Heifers were included in their study (Oltenacu et al., 1991) only if they eventually had at least 2 lactations;

Table 11. Heritability and genetic correlation estimates for linear and threshold models

\begin{tabular}{|c|c|c|c|}
\hline & & Linear & Threshold \\
\hline \multirow[t]{3}{*}{ Heritabilities (\%) } & First service only & 0.5 & 1.0 \\
\hline & All services, confirmed matings ${ }^{1}$ & 0.4 & 0.7 \\
\hline & All services, including unconfirmed ${ }^{2}$ & 0.4 & - \\
\hline \multirow[t]{2}{*}{ Genetic correlations } & Heifer CR, cow $\mathrm{CR}^{3}$ & 0.39 & - \\
\hline & Heifer CR, milk yield ${ }^{4}$ & -0.19 & - \\
\hline
\end{tabular}


such an edit would certainly reduce the genetic standard deviations in the denominator of the correlation.

The genetic correlation of heifer CR on first service and first-lactation milk yield was -0.19 , implying that selection for milk yield ignoring fertility will decrease heifer fertility as well as cow fertility. Oltenacu et al. (1991) estimated a genetic correlation of -0.13 between heifer CR on first service and milk yield in the first 100 $\mathrm{d}$ of first lactation, for their sample of Swedish Red and Whites.

Estimates of the genetic correlation between cow CR on first service and milk yield vary in the literature but are generally larger in magnitude than the -0.19 found in this study for heifer CR. Berry et al. (2003), for example, reported a -0.29 genetic correlation between cow $\mathrm{CR}$ on first service and milk yield, whereas Veerkamp et al. (2001) found a correlation of -0.49 . The lower heritability of heifer $\mathrm{CR}$, the modest correlation with cow $\mathrm{CR}$, and a genetic correlation with milk yield that is smaller in magnitude than that for cows might be explained by genes that are activated by lactation (which increases the heritability in cows and magnitude of correlation with milk yield) but are not active in the nonlactating heifer.

There are currently no immediate plans at AIPL to implement a US genetic evaluation for heifer fertility. Although improvement of heifer fertility would be of benefit to dairy farmers, US heifers currently have a mean CR of about 55 to $60 \%$, compared with a CR of about 30 to $35 \%$ for US Holstein cows. Furthermore, results from this study have indicated that selection for improved cow fertility, either with DPR or possibly with a cow $\mathrm{CR}$ evaluation in the future, will improve heifer CR as well. In addition, the amount of data for heifers is still somewhat limited. Although the $529 \mathrm{Hol}-$ stein bulls categorized as active in November 2005 had a mean of 340 daughters with heifer breedings, $70 \%$ of the active bulls had 100 or fewer daughters and $60 \%$ had 50 or fewer daughters. Thus, the low heritability and somewhat limited scope of heifer data (only 2 processing centers reporting) also lend themselves to the argument of focusing primarily on cow fertility at least in the near future, rather than providing a separate evaluation for heifer fertility per se.

One of the reasons for this research was to provide some preliminary information as to how breeding data for heifers might be used in US evaluations. With the availability of Format 5 data, future research will examine the possibility of implementation of a US genetic evaluation for cow CR. With unequal heritabilities and only a modest genetic correlation with cow fertility, the heifer breedings could not be simply included along with cow breedings in a single-trait genetic evaluation for female CR. Perhaps the best use of the heifer breed- ings would be to use them as a correlated trait in an evaluation for cow $\mathrm{CR}$ and report only breeding value estimates for cow CR. This would improve accuracy of cow CR evaluations, especially for young bulls that could possibly have more daughters with reported heifer breedings than cow breedings. Multitrait evaluations, treating cow and heifer breedings as separate traits, may also be an avenue for inclusion of heifer breedings in the development of a phenotypic predictor of service sire fertility.

\section{CONCLUSIONS}

Mean AI CR for US Holstein heifers is about 57\%. For the binary trait heifer CR, differences in means and significance tests between linear and logistic models were almost nonexistent. Factors affecting heifer $\mathrm{CR}$, in order of importance, include year, heifer age, month, herd, stud, service sire age, and inbreeding in the heifer, service sire, and mating. Month effects were smaller for heifers than for cows and may be due more to variation in management than variation in climate. Although highest CR was observed in the spring for heifers, differences amongst seasons are relatively small. The intermediate age of 15 to $16 \mathrm{mo}$ at breeding maximizes heifer CR. The most pronounced effect of heifer age is that breedings at 26 mo of age or older result in a $13 \%$ lower CR than breedings at 15 to $16 \mathrm{mo}$. Age of service sire also has an intermediate optimum of 3 to $5 \mathrm{yr}$. An interaction exists between service sire inbreeding and service sire age. Higher inbreeding in the service sire results in lower heifer CR. However, bulls with the highest levels of inbreeding are apparently culled more intensely (based on fertility) because at ages greater than $1.5 \mathrm{yr}$, bulls at the highest levels of inbreeding actually have higher CR than bulls with a midlevel of inbreeding. Greater inbreeding in both the (potential) embryo and the heifer also result in lower CR, although the effects are relatively small. Variation among the 5 major AI studs in the United States is relatively small with mean heifer CR ranging only $2.8 \%$ across those studs. Holstein heifers bred to Holstein bulls conceive better than Holstein heifers bred to either Brown Swiss or Jersey bulls. However, for a combination of all other breeds of service sire (primarily Ayrshire, Guernsey, and Milking Shorthorn), heifer CR was better than for matings to Holstein service sires. Variation among US herds for Holstein CR is considerable but $88 \%$ of all herds fall in the range of 40 to $70 \%$.

The heritability of heifer CR is low. The linear model estimate of heritability for heifer CR on first service was $0.5 \%$ and the threshold model estimate was $1.0 \%$ for the underlying scale, both of which are lower than 
most published estimates of heritability for cow CR. Heritability for first service is higher than heritability for all services combined. Genetic correlation estimates of heifer CR on first service with cow CR on first service and with first-lactation milk yield were 0.39 and -0.19 , respectively. Selection on either the currently available US DPR evaluations for cow fertility or on cow CR will improve heifer fertility. Thus, there are currently no immediate plans to implement a US genetic evaluation for heifer CR. Heifer breedings could not be combined in a single-trait model with cow breedings in a genetic evaluation for CR because of differing heritabilities and a genetic correlation considerably less than 1 . Nonetheless, a possible future use of heifer breedings would be to include them as a correlated trait for genetic evaluation of cow CR.

\section{ACKNOWLEDGMENTS}

Richard Saacke is gratefully acknowledged for numerous conversations on reproductive physiology and on-farm practices. Appreciation is also extended to Steve Kachman for discussions on estimation in a logistic model. Also thanks to Ignacy Misztal for the use of his cblup90reml program and to Keith Boldman and Dale VanVleck for the use of their MTDFREML program. Thanks also to Duane Norman for a careful and thorough review and to Mike Schutz for providing an additional prompt review. Dairy Records Management Systems and AgSource are acknowledged for their supply of Format 5 data as are the American dairy farmers who pay for data collection in the United States.

\section{REFERENCES}

Andersen-Ranberg, I. M., B. Heringstad, D. Gianola, Y. M. Chang, and G. Klemetsdal. 2005. Comparison between bivariate models for 56-day nonreturn and interval from calving to first insemination in Norwegian Red. J. Dairy Sci. 88:2190-2198.

Andersen-Ranberg, I. M., B. Heringstad, G. Klemetsdal, M. Svendsen, and T. Steine. 2003. Heifer fertility in Norwegian dairy cattle: Variance components and genetic change. J. Dairy Sci. 86:2706-2714.

Animal Improvement Programs Laboratory (AIPL). 2005. Genetic and phenotypic trends. Online: http://aipl.arsusda.gov/dynamic/ trend/current/trndx.html. Accessed Nov. 2, 2005.

Badinga, L., R. J. Collier, W. W. Thatcher, and C. J. Wilcox. 1985. Effects of climatic and management factors on conception rate of dairy cattle in subtropical environment. J. Dairy Sci. 68:78-85.

Berry, D. P., F. Buckley, P. Dillon, R. D. Evans, M. Rath, and R. F. Veerkamp. 2003. Genetic relationships among body condition score, body weight, milk yield, and fertility in dairy cows. J. Dairy Sci. 86:2193-2204.

Bishop, M. W. H. 1970. Aging and reproduction in the male. J. Reprod. Fert. (Suppl. 12):65-87.
Cassell, B. G., V. Adamec, and R. E. Pearson. 2003. Maternal and fetal inbreeding depression for 70-day nonreturn and calving rate in Holsteins and Jerseys. J. Dairy Sci. 86:2977-2983.

Collett, D. 2003. Modelling Binary Data. 2nd ed. Chapman \& Hall/ CRC, Washington, DC.

Donovan, G. A., F. L. Bennett, and F. S. Springer. 2003. Factors associated with first service conception in artificially inseminated nulliparous Holstein heifers. Theriogenology 60:67-75.

Falconer, D. S. 1989. Introduction to Quantitative Genetics. 3rd ed. Longman Scientific \& Technical, Essex, UK.

Hahn, J., R. H. Foote, and G. E. Seidel, Jr. 1969. Quality and freezability of semen from growing and aged dairy bulls. J. Dairy Sci. 52:1843-1848.

Jorjani, H. 2005. Preliminary report of Interbull pilot study for female fertility traits in Holstein populations. Online: http://www-interbull.slu.se/bulletins/framesida-pub.htm. Accessed Nov. 18, 2005.

Kuhn, M. T., J. L. Hutchison, and J. S. Clay. 2004. Prediction of service sire fertility. J. Dairy Sci. 87(Suppl. 1):412. (Abstr.)

Maltecca, C., H. Khatib, V. R. Schutzkus, P. C. Hoffman, and K. A. Weigel. 2006. Changes in conception rate, calving performance, and calf health and survival from use of crossbred Jersey $\times$ Holstein sires as mates for Holstein dams. J. Dairy Sci. 89:2747-2754.

Oltenacu, P. A., A. Frick, and B. Lindhe. 1991. Relationship of fertility and milk yield in Swedish cattle. J. Dairy Sci. 74:264-268.

Raheja, K. L., E. B. Burnside, and L. R. Schaeffer. 1989. Heifer fertility and its relationship with cow fertility and production traits in Holstein dairy cattle. J. Dairy Sci. 72:2665-2669.

Rankin, T. A., W. R. Smith, R. D. Shanks, and J. R. Lodge. 1992. Timing of insemination in dairy heifers. J. Dairy Sci. 75:2840 2845.

Ron, M., R. Bar-Anan, and G. R. Wiggans. 1984. Factors affecting conception rate of Israeli Holstein cattle. J. Dairy Sci. 67:854-860.

Salisbury, G. W., N. L. VanDemark, and J. R. Lodge. 1978. Physiology of Reproduction and Artificial Insemination of Cattle. 2nd ed. W.H. Freeman and Company, San Francisco, CA.

Sartori, R., R. Sartor-Bergfelt, S. A. Mertens, J. N. Guenther, J. J. Parrish, and M. C. Wiltbank. 2002. Fertilization and early embryonic development in heifers and lactating cows in summer and lactating and dry cows in winter. J. Dairy Sci. 85:2803-2812.

SAS Institute. 2004. Online Doc. Version 9.1.2. SAS Inst., Inc., Cary, NC.

Tanabe, T. Y., and G. W. Salisbury. 1946. Influence of age on breeding efficiency. J. Dairy Sci. 29:337-344.

Tenhagen, B.-A., M. Drillich, R. Surholt, and W. Heuwieser. 2004. Comparison of timed AI after synchronized ovulation to AI after estrus: Reproductive and economic considerations. J. Dairy Sci. 87:85-94.

Thompson, J. R., R. W. Everett, and N. L. Hammerschmidt. 2000. Effects of inbreeding on production and survival in Holsteins. J. Dairy Sci. 83:1856-1864.

VanRaden, P. M., A. H. Sanders, M. E. Tooker, R. H. Miller, H. D. Norman, M. T. Kuhn, and G. R. Wiggans. 2004. Development of a national genetic evaluation for cow fertility. J. Dairy Sci. 87:2285-2292.

Veerkamp, R. F., E. P. C. Koenen, and G. De Jong. 2001. Genetic correlations among body condition score, yield, and fertility in first-parity cows estimated by random regression models. J. Dairy Sci. 84:2327-2335.

Weigel, K. A. 2004. Improving the reproductive efficiency of dairy cattle through genetic selection. J. Dairy Sci. 87(E Suppl.):E86-E92.

Weigel, K. A., and R. Rekaya. 2000. Genetic parameters for reproductive traits of Holstein cattle in California and Minnesota. J. Dairy Sci. 83:1072-1080.

Weller, J. I., and M. Ron. 1992. Genetic analysis of fertility traits in Israeli Holsteins by linear and threshold models. J. Dairy Sci. 75:2541-2548. 